\title{
Approach-avoidance conflict behavior as a function of prior shock stimulation'
}

\author{
WILLIAM TERRIS AND RUSSELL EMZIE
}

UNIVERSITY OF OKLAHOMA

Albino rats received a series of spaced 1-sec. shocks administered in their homecages for five consecutive days, and were later tested in an approach-avoidance conflict situation with either shock or airblast. Compared to control groups the prior-shock Ss were initially less sensitive to the effects of electric shock in the conflict situation.

An extensive amount of research indicates that electric shock stimulation increases subsequent responsiveness to aversive stimulation (e.g., Kurtz \& Walters, 1962; Terris \& Wechkin, 1967). These results have been interpreted to indicate that ". . . experiences of intense fear predispose animals to react with increased fear in subsequent encounters with aversive stimulation" (Kurtz \& Walters, 1962, p. 1078).

Three aspects of the procedure typically used to test for the effects of electric shock deserve attention. The first is that the use of the same aversive stimulus in both the stimulation and conflict testing phases of an experiment does not permit one to test for general changes in responsiveness to aversive stimulation. In order to conclude that an effect is general in nature It is necessary to show that experience with a particular aversive stimulus alters responsiveness to more than one aversive stimulus. The second aspect involves the question of whether the similarity between the stimulation apparatus and the test apparatus can account for the apparent increase in emotional responsiveness. Other investigators (e.g., Kurtz \& Walters) have attempted to rule out stimulus generalization by using highly dissimilar apparatus in the stimulation and test phases. However, there is always the possibility that certain stimulus aspects may be present in both situations (e.g., stimuli associated with handling). The third aspect concerns the duration of the electric shock used to induce fear in the stimulation phase. In most experiments the shock has been 5 sec. in length (e.g., Kurtz \& Walters) but this is in reality a series of discrete shocks since the animal actually breaks contact with the grid many times during this period. It is possible under these conditions that shock, or the internal cues associated with shock, become conditioned stimuli for a conditioned emotional response. A series of widely spaced shocks would not be expected to have this effect since the interval between the $\mathrm{CS}$ and UCS would be too long for conditioning to occur.

The purpose of this experiment was to determine the effect of a series of spaced 1-sec. shocks (administered to the animals in thein home cages) upon subsequent responsiveness to more than one type of aversive stimulus.

\section{Method}

The Ss were 17 female and 12 male Holtzman albino rats, approximately 120 days of age at the start of the experiment. The Ss were housed in $7 \mathrm{x}$ $7 \times 9$ in. individual cages from weaning until the start of the experiment.

On Day 1 of the experiment, the home cage for each $S$ was inverted and placed on a grid floor consisting of 1/8-in. brass rods, spaced $1 / 2$ in. apart. The Ss were housed in these inverted home cages for the entire experiment. Free access to food and water was permitted on Days 1-5 but on Day 6 a 23-hr. food deprivation schedule was initlated and maintained throughout the experiment. On Day 8, a taming procedure was initiated in which the Ss were handled in the presence of food for two 20-min. sessions per day until the Ss could be picked up without difficulty.

On the 11th day, approach training began with the Ss trained to approach food located at the end of an enclosed runway, $3 \mathrm{ft}$. long, 4-1/2 in. wide, and 5 in. high. The runway was constructed of flat graypainted wooden sides and a hinged gray wooden frame top covered with wire mesh. The entire floor of the runway consisted of $1 / 8-$ in. brass rods spaced $1 / 2$ in. apart.

Each S was given one approach trial on Day 11 and four trials on Days 12-25. Each trial consisted of placing the $S$ into the start section of the runway and recording the time taken to approach the purina wet mash located at the end of the runway (consummatory latency). On the first trial Ss were allowed $60 \mathrm{sec}$. consummatory time, while on all subsequent trials, 30 sec. were allowed.

On Days 15-19 of the experiment, 14 of the Ss were subjected to a series of $30.4 \mathrm{~mA}$ electric shocks of 1-sec. duration. These electric shocks were administered over a 21-min. period with an intershock interval ranging from 11 to $77 \mathrm{sec}$. with an average interval of $41 \mathrm{sec}$. The shock was administered to the animals in the home cages approximately $8 \mathrm{hr}$. prior to the approach training in the runway. The home cages were wired to a shock source in an adjoining room which allowed the $\mathrm{E}$ to administer the shock without entering the room. The shock source consisted of a $1200 \mathrm{~V}$ transformer powered by a variable auto transformer with the output fed Into a full wave rectifier. The output was fed through 
a 2.2 megohm resistor and a 0-1.0 $\mathrm{mA}$ meter, both of which were in series with the $S$.

Aversive stimulation was introduced into the runway on Day 26, with the Ss receiving either a 1-sec. .4 mA electric shock or a 1-sec. airblast delivered from an airgun having a source pressure of $28 \mathrm{lbs.} / \mathrm{sq}$. in. and an opening of $1 / 8 \mathrm{in}$. The aversive stimulus was administered when $S^{\prime} s$ nose touched the food dish. The trial was concluded if an $S$ did not approach the food within $6 \mathrm{~min}$. or if it did not return to the food within $6 \mathrm{~min}$. after receiving the aversive stimulus. Only one aversive stimulus was administered on each trial, and only one trial per day was given on Days 26 through 30.

In all, there were four main treatment groups. Two of the groups received shock in their home cage with the first tested in the runway with shock (SS group, $N=8$ ), and the second with airblast (SA group, $N=6$ ). The other two groups received no shock in their home cage and were tested with either shock (NS group, $\mathrm{N}=8$ ) or airblast (NA group, $\mathrm{N}=7$ ) in the conflict situation.

\section{Resulis and Discussion}

A series of $t$ tests which compared the consummatory latencies of the Ss receiving shock in their home cages with those of the nonshock controls during approach training were not significant: (1) prior to the introduction of shock into the home cage $\left(t_{t r i a l} 1=\right.$ .30 , df $=27$ ), (2) during the period in which the shock was administered in the home cage ( $t_{\text {trial }} 14=1.10$, $d f=27$; $t_{\text {trial }} 33=.76, d f=27$ ), (3) on the last approach trial prior to the introduction of aversive stimulation Into the runway ( $t_{\text {trial }} 57=.44, d f=27$ ).

In order to determine the effect of the first aversive stimulus received in the runway, an analysis of variance was performed on the reconsummatory latencies on Day 26 as a function of the type of aversive stimulus received in the home cage (home cage treatment) and the type of aversive stimulus received in the runway (runway treatment). The $F$ ratio for home cage treatment was significant $(F=5.35, d f=1 / 21$, $p<.05)^{2}$ with the animals receiving shock in their home cages having a mean reconsummatory latency of $47.8 \mathrm{sec}$. while the nonshock controls had a mean of $135.5 \mathrm{sec}$. The other $F$ ratios were not significant. In order to determine if shock in the home cage had a general effect (1.e., resulted in decreased responsiveness to subsequent airblast as well as to shock) it was necessary to separately compare the two treatment groups tested with shock (i.e., SS vS NS) and the two tested with airblast (i.e., SA vs NA). While the SS group had a significantly shorter mean reconsummatory latency than the NS group
$\overline{\mathrm{X}}_{\mathrm{SS}}=41.6, \overline{\mathrm{X}}_{\mathrm{NS}}=180 \mathrm{3} ; \mathrm{F}$ contrast $=6.99, \mathrm{df}=1 / 21$, $p<.05)$, the difference between the SA and NA groups did not approach significance $\left(\overline{\mathrm{X}}_{\mathrm{SA}}=56.1, \overline{\mathrm{X}}_{\mathrm{NA}}=84.3\right.$, $F$ contrast $=.38, d f=1 / 21$ ). These results indicate that animals receiving shock in their home cages were less disrupted by shock in the runway than the nonshock controls and suggest that the decrease in responsiveness to aversive stimulation was limited to the previously experienced stimulus.

The consummatory latencies occurring after the introduction of the aversive stimulus into the runway situation did not meet the assumptions necessary for a parametric analysis due to a large number of Ss in some groups not responding on several trials. Therefore, a median consummatory latency was obtained for each $S$ for the four trials following the introduction of the aversive stimulus into the runway. Mann-Whitney U tests showed that the Ss tested with shock in the runway had significantly longer consummatory latencies than did the Ss tested with airblast $(p<.01)$. The differences between the NS and SS groups and between the NA and SA groups did not approach significance.

The results of this experiment are not consistent with the hypothesis that experiences with fear provoking stimuli predispose an animal to react with greater fear in subsequent encounters with aversive stimulation. On the contrary, they suggest that under certain circumstances experience with a fear producing aversive stimulus may result in less responsiveness to subsequent aversive stimulation. The most obvious procedural differences between the present experiment and other studies which have obtained the opposite results, are the location, duration, and number of days of initial electric shock stimulation.

Regardless of whether the decrease in responsiveness to electric shock stimulation is due to one or a combination of these three variables, the results of this experiment and of a previous study (Terris \& Wechkin) limit the generality of Kurtz' hypothesis. Further research is needed to determine the condithons under which emotional responsiveness to aversive stimulation may be increased or decreased.

\section{References}

Kurtz, K., \& Walters, G. The effects of prior fear experiences on an approach-avoidance conflict. J. comp. physiol. Psychol., 1962, 55, 1075-1078.

Terris, W., \& Wechkin, S. Approach-avoidance conflict behavior as a function of prior experience with mild or intense electric Notes

shock stimulation. Psychon. Sci., 1967, 7, 39-40.

1. This research was supported in part by Public Health Service Mental Health Grant No. 12052-01.

2. Probability statements are based upon two-tailed tests. 